\title{
EL QUIJOTE COMO UTOPÍA NECESARIA: LA MIRADA DE ADOLFO SÁNCHEZ VÁZQUEZ
}

\author{
CARMEn MAdORRÁn AYERra \\ Universidad Autónoma de Madrid \\ carmen.madorran@uam.es
}

\section{El concepto de utopía en la filosofía de Adolfo SÁnchez VÁzQuez}

lo largo de la obra de Sánchez Vázquez podemos encontrar una preocu-
pación por la utopía. En su trabajo de 1975 Del socialismo científico al
socialismo utópico leemos ya algunos de los rasgos definitorios del modo en que la concebía. Pero además, en los años noventa escribió varios artículos sobre la cuestión de la utopía, que constituyen su particular estudio sobre la misma. Algunos de ellos se encuentran recogidos en la tercera parte de su libro Entre la realidad y la utopía. Ensayos sobre política, moral y socialismo (1999). Allí, junto a la lectura utópica del libro de Cervantes que se nos propone, el filósofo trata la cuestión del socialismo como utopía y reafirma la necesidad de una utopía semejante en el siglo XxI. Tampoco olvida ofrecer su aportación al debate abierto en aquellos años sobre el fin de la historia y el fin de cualquier alternativa posible al capitalismo, o en definitiva, el fin de las utopías. Como muestra del interés que le despertaba este tema, cabe señalar el hecho de que en sus últimos años de vida decidiera retomar uno de sus artículos de los noventa, titulado «La utopía de Don Quijote» ${ }^{1}$, para impartir una conferencia en Málaga en el año 2005. El texto de la misma fue publicado después con el título Don Quijote como utopía.

Es sabido que el término "utopía" nació en 1516, como título de la obra en la que Tomás Moro vertía una crítica social a la Inglaterra de su tiempo, y que daba asimismo nombre a la armoniosa isla imaginaria que describía. La traducción de las palabras griegas que forman "utopía” (ou y tópos) sería 'no hay tal lugar', tal y como lo escribiera Quevedo en el prólogo de la primera edición castellana de

\footnotetext{
Este texto se había presentado en el IV Coloquio Cervantino Internacional celebrado en la ciudad mexicana de Guanajuato.
}

Edad de Oro, XXXIV (2015), pp. 85-97, ISSN: 0212-0429 - DOI http://dx.doi.org/10.15366/edadoro2015.34.005 
la obra de Moro, de 1637 (Sánchez Vázquez 1999; Muguerza 2010). En la tradición utópica se entremezclan la crítica al presente o crítica de la sociedad contemporánea con la descripción más o menos pormenorizada de la sociedad futura, la sociedad mejor y deseable. Esta, a su vez, puede situarse en un pasado perdido y en muchas ocasiones atemporal; o bien puede representar una proyección para construir en el futuro. Adolfo Sánchez Vázquez nos propone un recorrido histórico que refleja los rasgos generales de las distintas formulaciones del concepto de utopía en distintas épocas. En primer lugar, habría que considerar las utopías clásicas o premodernas, cuyo rasgo compartido sería la perfección y por tanto la imposibilidad de realización del ideal. La más destacada es la formulada por Platón, cuya utopía «no es algo que pueda, deba o haya de realizarse. Está dada como realidad, es decir, con la realidad más alta y verdadera para Platón: la ideal» (Sánchez Vázquez 1975: 10). Esta completa separación entre dos mundos opuestos -el imperfecto de la realidad terrenal y el perfecto del reino de las Ideasimprime inevitablemente en este tipo de utopías la imposibilidad de la realización del ideal en la tierra.

Sánchez Vázquez considera fundamental la conexión entre la utopía y la acción, y en consecuencia presta especial atención a tres modelos generales de utopía que se habrían sucedido históricamente: las utopías modernas, las de los socialistas utópicos y las utopías marxistas-comunistas. Sin embargo, no por ello olvida el puente entre las utopías clásicas y las modernas que supuso la utopía anabaptista de Thomas Münzer. Su relevancia estriba en que pese a mantener la división entre lo real y lo ideal (y por tanto la doble dimensión humana-divina), la realización del ideal no está solo en el cielo, sino también en la tierra: «Lo trascendente desciende a este mundo real, pero a condición de que los hombres luchen por su realización. Tal es el significado histórico de la rebelión de los campesinos alemanes del siglo $\mathrm{XVI}^{2}$. La utopía mira con un ojo al futuro y con otro, al presente» (Sánchez Vázquez 1999: 293). Apartadas de cualquier contenido trascendente, las utopías modernas - renacentistas e ilustradas- se caracterizan por centrarse en la dimensión terrenal, concretamente en las consecuencias que supuso para los campesinos la transición del feudalismo al capitalismo. De todas ellas, cabe destacar las de Moro, Campanella, Bacon o Morelly, que se caracterizan por una dura crítica de la realidad existente así como por la propuesta de horizontes y modelos alternativos. Sánchez Vázquez señala que en ellas ya se ha producido el cambio fundamental respecto a las anteriores, pues llevarían inserta una fuerte voluntad de realización de lo utópico. Ahora bien, la realización del ideal se estima posible por medio de la persuasión, el conocimiento y especialmente de la educación, en la que los utopistas ilustrados depositaron una confianza plena. Es precisamente

También conocida como "guerra de los campesinos alemanes" o "revolución del hombre común". Münzer fue uno de sus protagonistas, siendo por ello detenido, torturado y decapitado. 
esta fe en el poder de la razón y la educación para la formación de una nueva humanidad la que hizo que muchos de ellos descartasen el papel que la acción y la práctica pueden desempeñar para el advenimiento de la sociedad nueva.

En el siglo XIX tomarían el testigo los socialistas utópicos (Saint-Simon, Owen, Fourier, Cabet), que reaccionaron con vigor ante las condiciones de vida y trabajo que había creado la Revolución Industrial. El inconveniente que Sánchez Vázquez indica en este caso es que pese a su prolijidad en la descripción de las nuevas sociedades, sus autores desconocían profundamente cómo funcionaba el sistema que criticaban. En el plano de la práctica destacaron por la fundación de comunidades o escenarios de futuro a modo de anticipaciones de la sociedad por venir. Sin embargo, estos autores continúan teniendo una esperanza excesiva en la educación a través del ejemplo y el cambio gradual que este iba a generar. También en el XIX vieron la luz algunas obras de lo que puede considerarse utopismo revolucionario como el de Weitling y Blanqui; y de los padres del utopismo anarquista o libertario, con Bakunin y Kropotkin como representantes. Se trataría en estos casos de utopías realizables que habrían centrado su esperanza emancipatoria en la revolución como acto único y excepcional.

La utopía socialista y comunista (entre cuyos defensores cuenta a Marx, Engels y autores posteriores del "marxismo cálido", según el término de Bloch) también describiría una sociedad necesaria, deseable y posible. Frente a otras corrientes de interpretación de las obras de Marx y Engels, Sánchez Vázquez defiende que:

La utopía, o más exactamente un aspecto o un ingrediente utópico no solo forma parte del pensamiento de Marx y del marxismo "cálido", sino que constituye un aspecto o componente esencial de él, aunque en unidad indisoluble con otros que también lo son, a saber: la crítica de lo existente, el conocimiento de la realidad que se critica y pretende transformar, y su vocación práctica o vinculación con la acción. Hay, pues, una utopía en Marx, y la hay como proyecto de emancipación o de sociedad futura; es decir, como alternativa social al sistema de dominación y explotación capitalista. (1999: 296)

Sánchez Vázquez critica que en esta utopía socialista también hay elementos abstractos y especulativos que hacen que contenga aspectos imposibles de realizar. Se refería fundamentalmente a la cuestión de la enajenación y cómo podría superarse totalmente, a la extinción del Estado, a la idea del proletariado como sujeto exclusivo de la revolución o a la mágica desaparición de los conflictos étnicos y nacionales al resolverse las contradicciones de clase. Otro rasgo irrealizable que encuentra en la propuesta de Marx y Engels - y que tiene especial relevancia en nuestros días- es su dependencia de la abundancia. Es decir, si la tarea de satisfacer las necesidades de todos (objetivo declarado de esta doctrina) requiere de un desarrollo ilimitado de las fuerzas productivas, resulta del todo «incompatible 
con el imperativo ecológico de no destruir, con ese desarrollo, la base natural de la existencia humana» (1999: 297).

Conocemos ya los rasgos fundamentales por los que Sánchez Vázquez diferencia unas utopías de otras: «por su distinta relación con el tiempo y la realidad, así como por su función o potencial práctico [...] de acuerdo con su posibilidad o imposibilidad de realizarse podemos considerar a su vez [las utopías] como positivas o negativas» (1999: 312). Esta división de las utopías entre aquellas realizables (positivas) e irrealizables (negativas) ha sido compartida por autores como Javier Muguerza:

La fantasía de aquel utopista decimonónico que proyectaba en su imaginación convertir el agua de los océanos en limonada no nos parece realizable, y hasta nos hace dudar de la salud mental de quien propone un proyecto utópico como ese que juzgamos sencillamente un disparate; pero la utopía de construir una sociedad más justa que la actual —esto es, más libre y más igualitaria, y en definitiva más acorde con lo que conjuntamente estimemos que es nuestra dignidad humana- no es por principio irrealizable, por más que raramente nos acerquemos a su realización y en cualquier caso nunca la hayamos visto realizada en toda su plenitud imaginable. Que es la razón por la que su incompleta e insuficiente realización nos deja invariablemente insatisfechos y hasta acaso no tengamos otro remedio que vivirla como una permanente frustración... insatisfacciones y frustraciones éstas que generan inevitablemente esa contrapartida de la utopía en que vendría a consistir a fin de cuentas la melancolía. (Muguerza 2010: 74, cursiva del original)

Pues bien, habida cuenta de lo anterior, las principales características que buscaremos de la mano de Sánchez Vázquez en el texto de Cervantes son las de la utopía moderna y contemporánea que remite a una sociedad imaginaria y que supone además una crítica de la realidad existente, siendo subversiva por definición. Esta utopía es valiosa y deseable por contraste con lo real, que se rechaza también mediante el repudio de sus valores. Por tratarse de una realidad mejor que la existente, la utopía no es pero debe ser, y por tanto no solo critica lo que hay, sino que supone una alternativa imaginaria a los males del presente. Precisamente porque debe ser, lleva implícita la aspiración a realizarse aquí y ahora. Lleva esa llamada a la acción, a la praxis, tan necesaria (Sánchez Vázquez 2007: 22).

\section{El QuiJote como utopía}

Autores de muy distintos procederes han acudido al Quijote con objetivos igualmente dispares. Pues bien, la pregunta que plantea en este caso Adolfo Sánchez Vázquez es la siguiente: ¿puede encontrarse una determinada forma utópica en la obra de Cervantes? Independientemente de la intención del autor, cree más 
interesante lo que la obra tenga que decirnos a los lectores (en ese sentido, los propósitos del autor pueden no coincidir con los resultados). Veamos entonces si podemos leer la novela de Cervantes como una utopía, y qué es lo que mueve a don Quijote a actuar como lo hace. Para Sánchez Vázquez, además, la idoneidad de preguntar por la utopía cuando lo está haciendo —en 1990 - viene marcada por el pragmatismo y el fracaso de los grandes proyectos de transformación social. No eran pocos los que escribían entonces defendiendo que todo empeño utópico era absurdo y carente de sentido: «Preocupados por el destino de la utopía en tiempos de desencanto, como los nuestros, en que se busca sepultarla, queremos hoy tomar el pulso a la obra de Cervantes, y ver si late de un modo utópico» (Sánchez Vázquez 1999: 261). No se nos escapa que en esa atinada pregunta anidaba la preocupación por la posibilidad de toda utopía y, por tanto, estaba en juego algo que trascendía la obra de Cervantes.

Como hemos visto, uno de los rasgos de utopía que maneja Sánchez Vázquez es la presencia de una descripción de la sociedad imaginaria. Maravall, en su libro Utopía y contrautopía en El Quijote, aclara que, «como es normal en tantos programas de reforma, la novedad consiste en un restablecimiento: volver a traer al presente la imagen de una sociedad perfecta entrevista apenas en una lejanía imprecisa, indefinible, prácticamente sin tiempo ni lugar» (Maravall 1976:169). Leyendo el discurso de don Quijote a los cabreros bajo esta luz, reparamos en esa referencia a algún tiempo pasado que fue mejor y que se caracteriza por la ignorancia de las palabras "tuyo" y "mío":

Dichosa edad y siglos dichosos aquellos a quien los antiguos pusieron nombre de dorados, y no porque en ellos el oro, que en esta nuestra edad de hierro tanto se estima, se alcanzase en aquella venturosa sin fatiga alguna, sino porque entonces los que en ella vivían ignoraban estas dos palabras de tuyo y mío. Eran en aquella santa edad todas las cosas comunes; a nadie le era necesario para alcanzar su ordinario sustento tomar otro trabajo que alzar la mano y alcanzarle de las robustas encinas. Todo era paz entonces, todo amistad, todo concordia [...] No había la fraude, el engaño ni la malicia mezclándose con la verdad y llaneza. La justicia se estaba en sus propios términos, sin que la osasen turbar ni ofender los del favor y los del interese, que tanto ahora la menoscaban, turban y persiguen. La ley del encaje aún no se había sentado en el entendimiento del juez, porque entonces no había qué juzgar, ni quien fuese juzgado. Las doncellas y la honestidad andaban, como tengo dicho, por dondequiera, sola y señora, sin temor que la ajena desenvoltura y lascivo intento le menoscabasen, y su perdición nacía de su gusto y propia voluntad. (Cervantes 1987 [I, 11]:220-224)

Adolfo Sánchez Vázquez encuentra aquí la idea de la sociedad futura caracterizada por la ausencia de la propiedad privada y la comunidad de los bienes, además de por la liberación del trabajo, que se habría vuelto innecesario. Al no ser la 
anterior una descripción del presente de Cervantes ni de ningún otro tiempo reconocible, cobra sentido la propuesta del filósofo de tomar este discurso como una llamada utópica, descriptora de una realidad mejor y ansiada para el futuro. En un sentido similar, Chul Park ha considerado que esta edad dorada no es otra cosa que el comunismo primitivo: «la primera formación social del género humano, en donde no existía la propiedad ni la lucha de clases, en donde reinaban la libertad e igualdad social, la paz y la seguridad, la justicia y la verdad, la concordia y la amistad» (Park 2004: 180). Por su parte, Muguerza defiende que «la libertad de que Cervantes hace hablar a don Quijote parecería presuponer una igualdad de base [...] muy apropiadamente, se ha querido y podido ver [en este fragmento] un precedente del Discurso acerca del origen de la desigualdad de Rousseau» (Muguerza 2010: 74).

La lectura que de este pasaje hace Maravall (1976) podría parecer ligeramente distinta. A su entender, lo que defendería aquí don Quijote sería la libertad de los individuos para tomar los bienes que la naturaleza les ofrece, pero no tanto porque se trate de bienes colectivos, sino porque están ahí disponibles para todos con la limitación moral de no tomar más de lo que uno necesita. No deja de ser interesante que precisamente la descripción que Maravall hace de la libertad de tomar los bienes de la naturaleza porque se ofrecen para todos por igual (bienes de acceso universal) es una de las características definitorias de lo que hoy consideramos un bien común, como el agua, el aire y los rayos de sol, por ejemplo. Por tanto, desde esta perspectiva no habría incompatibilidad alguna —más bien coincidencia - entre la interpretación que lee en el discurso de don Quijote una reivindicación del disfrute colectivo de los bienes comunes, y aquella que entiende que esa edad de oro reclama más bien la libertad de los individuos para tomar de la naturaleza lo que necesiten.

La descripción de aquella sociedad ideal se contrapone, como nos dice Sánchez Vázquez, a la crítica de la "sociedad de hierro" del presente de Cervantes, en la que dominarían las características opuestas a las descritas: el fraude, la injusticia y el engaño. Este sería el segundo rasgo utópico del Quijote, la profunda crítica a la sociedad de su tiempo que recorrería los discursos de don Quijote: «La actitud negativa del caballero andante hacia la época en que le correspondió llevar a cabo su elevada misión, se expresa en muchas partes de la obra, donde habla de "estos tan calamitosos tiempos" [I, 9], "estos nuestros detestables siglos" [I, 38] o, "la depravada edad nuestra" [II, 1]» (Park 2004: 182). Buen ejemplo de ello nos da que frente a la extendida medida de la valía en función de la riqueza o la hidalguía, don Quijote defienda reiteradamente la virtud y las acciones. Encontramos aquí una crítica a los valores de su tiempo, de inspiración humanista: «Sábete, Sancho, que no es un hombre más que otro si no hace más que otro» (Cervantes 1987 [I, 18]: 360). Esta misma idea aparece en otras ocasiones a lo largo de la obra: 
Haz gala, Sancho, de la humildad de tu linaje, y no te desprecies de decir que vienes de labradores, porque viendo que no te corres, ninguno se pondrá a correrte; y préciate más de ser humilde virtuoso que pecador soberbio. [...] Mira, Sancho, si tomas por medio a la virtud, y te precias de hacer hechos virtuosos, no hay para qué tener envidia a los que los tienen, príncipes y señores; porque la sangre se hereda, y la virtud se aquista, y la virtud vale por sí sola lo que la sangre no vale. (Cervantes 1987 [II, 42]: 583-584)

Como vemos, hay en el Quijote grandes dosis de crítica de la realidad concreta, tanto en el plano social y moral como en el de las instituciones, siendo la Iglesia una de las mayores perjudicadas en un momento en el que la crítica a la Iglesia podía conllevar un desenlace fatal. Gaos, en el tercer volumen de su edición crítica del Quijote, pone en tela de juicio que el propio Cervantes fuera católico, y si lo era, «distaba de serlo en la forma tradicional en que lo era la generalidad de los españoles de su época, no solo el vulgo, [como] resulta evidente por la continua sátira y burla que hace de sus prácticas y sus creencias. En esto Cervantes es algo más que "anticlerical”» (Gaos 1987a: 144). Muguerza subraya la audacia y el valor de Cervantes al escribir «en aquella España asfixiante y profundamente reaccionaria que le había tocado en suerte vivir» tales discursos utópicos a favor de los dos grandes valores, la libertad y la igualdad, sobre los que se asienta la idea misma de la justicia (Muguerza 2010: 73):

La libertad, Sancho, es uno de los más preciados dones que a los hombres dieron los cielos; con ella no pueden igualarse los tesoros que encierra la tierra ni el mar encubre; por la libertad, así como por la honra se puede y debe aventurar la vida, y, por el contrario, el cautiverio es el mayor mal que puede venir a los hombres. Digo esto, Sancho, porque bien has visto el regalo y la abundancia que en este castillo que dejamos hemos tenido; pues en mitad de aquellos banquetes sazonados y de aquellas bebidas de nieve me parecía a mí que estaba metido entre las estrecheces de la hambre, porque no los gozaba con la libertad que los gozara si fueran míos, que las obligaciones de las recompensas de los beneficios y mercedes recibidas son ataduras que no dejan campear al ánimo libre. ¡Venturoso aquel a quien el cielo dio un pedazo de pan sin que le quede obligación de agradecerlo a otro que al mismo cielo! (Cervantes 1987 [II, 58]: 797-798)

Ahora bien, Sánchez Vázquez no considera que haya una estricta separación entre la realidad y la utopía, sino que más bien una conduce a la otra. La percepción de lo que es, y la insatisfacción que genera, conduce a la visión de lo que debe ser; y a su vez, en ese ideal se encuentra la razón de que se critique lo que es. En el Quijote, ese camino de ida y vuelta, esa relación bidireccional entre lo que es y lo que debe ser no aparece formulada en un pasaje aislado, sino que impregna las intervenciones y acciones de don Quijote. La visión del mundo mejor 
debe realizarse, ese es el empeño del caballero andante que intenta reinstaurar la virtud. No consistiría en detenerse a recordar el pasado, sino en traer esa imagen ansiada al presente. Este es el giro característico de la utopía para Sánchez Vázquez, el cambio interesante que en este caso explora y encuentra en el Quijote: la utopía no como un asunto concerniente a la mera teoría, sino capaz de tomar un sentido eminentemente práctico, una llamada a la acción que acabarían de completarla.

Don Quijote no filosofa, reflexiona o especula acerca de lo que debe ser; ese no es su problema. La cuestión para él está en hacer entrar los principios y valores que firmemente, sin desmayo, ha asumido, en lo que es, en la realidad. Se trata para él de establecer efectivamente, aquí y ahora, en la tierra, el bien, la justicia, la paz, la verdad, la honestidad (Sánchez Vázquez 1999: 266). Y ese empeño, sin duda, requiere de una serie de aventuras para transformar lo real. Toda la obra de Cervantes estaría plagada de ejemplos e intentos quijotescos de introducir el bien o la justicia en un mundo dominado por sus opuestos. Sánchez Vázquez afirma con rotundidad que don Quijote es ante todo un hombre de acción que se mueve en el mundo real por la utopía que ha asumido, sin retroceder pese a los obstáculos y arriesgando incluso la vida. La narración de Cervantes aparece como la descripción del comportamiento práctico con que el hidalgo pretende realizar la utopía en su presente. Ni se trata en esta utopía quijotesca únicamente de criticar lo que hay, ni de soñar con lo que debería ser, sino más bien de actuar y transformar la realidad hasta realizar la utopía. Sin embargo, observa Sánchez Vázquez, cada uno de los intentos de realizar el bien en la tierra emprendidos por el caballero andante fracasan estrepitosamente. Aquellos a los que don Quijote pretende ayudar de alguna manera acaban por no recibir la reparación por la injusticia, y en algún caso peor que como estaban. Sánchez Vázquez se pregunta por qué fracasa una y otra vez don Quijote, ya que esos fracasos consecutivos parecerían sellar el destino de todo comportamiento utópico: «El quijotismo como ejemplo paradigmático de utopismo, parece estar condenado a la imposibilidad de tomar tierra» (Sánchez Vázquez 1999: 267). En este sentido, es interesante la lectura en la que Nabokov alerta del error que se esconde en esta extendida creencia de que Cervantes hizo fracasar, uno tras otro, los intentos de restaurar la virtud emprendidos por don Quijote. Para mostrar que ese punto de vista no puede seguir defendiéndose, realiza un estudio pormenorizado de las andanzas del caballero, en el capítulo «Victories and Defeats» de su Lectures on Don Quixote. Allí, concluye que el resultado final entre las victorias y las derrotas de don Quijote es un empate técnico: 20 a 20 (si se prefiere, lo ofrece también en términos de tenis, 6-3, 3-6, 6-4, 5-7). El quinto set nunca pudo jugarse, lamenta, por la muerte de Alonso Quijano. También en este apartado señala cómo en cada una de las dos partes de la obra el resultado queda igualmente en tablas, siendo en la primera parte trece victorias y 
trece derrotas las que disfruta y encaja don Quijote, y siete frente a otras tantas, las que le corresponden en la segunda. (Nabokov 1983: 110)

Aunque la perspectiva de Nabokov podría haber aportado un enfoque más esperanzador a la pregunta de Sánchez Vázquez por la utopía en el Quijote, el filósofo no duda de los continuados fracasos del antihéroe. En este sentido, defiende que las utopías destinadas irremediablemente al fracaso son las utopías absolutas, como la que describe don Quijote al hablar a los cabreros (un mundo armonioso en que se vive sin trabajo, donde la comida se obtiene en todas partes de la naturaleza, etc.). Sin embargo, considera que la utopía es posible si se entiende como la búsqueda de la realización del bien, la justicia o la concordia. Además, Sánchez Vázquez cree que hay que buscar el fracaso concreto de don Quijote en la forma en que lleva a cabo las acciones, además de en una serie de obstáculos con que se encuentra. El primero de los errores del caballero sería su inversión o deformación de lo real. Al tomar lo imaginado como realidad (esto es, ver gigantes donde hay molinos de viento), no se está haciendo un buen análisis de lo realmente existente, y ante eso no hay otra posibilidad que el fracaso. Además, se da en la obra una desproporción brutal entre los medios y los fines, una causa inevitable de fracaso en cada aventura, y en general en cualquier intento transformador. Otro de los defectos que lleva al fallo de la realización utópica de don Quijote es su fidelidad absoluta a los principios, por cuanto le impide adecuar sus actos a los cambios de la realidad. Sánchez Vázquez también repara en este análisis en un problema de gran calado y que tiene mucho que ver con su comprensión de la utopía realizable en cualquier lugar y tiempo, como es la insuficiencia del esfuerzo individual (en este caso de don Quijote). Para una labor tan tremenda como la realización del bien en la tierra, igual que para cualquier otra transformación social, es imprescindible un esfuerzo colectivo: «Carente de la solidaridad y la ayuda colectiva necesarias, ese esfuerzo está condenado al fracaso» (Sánchez Vázquez 1999: 268). También intervienen, como no podía ser de otro modo, algunos obstáculos sociales en el camino, como la hostilidad de la ideología absolutista que va cerrando las posibilidades de los ideales humanistas de raíz erasmista de don Quijote.

La locura del caballero, que tantos ríos de tinta ha generado, residiría para el filósofo español en ese empeño de realizar el bien y la justicia partiendo de una visión distorsionada de la realidad y contando con escasísimos medios a su alcance. Pese a ello, la tesis que defiende Sánchez Vázquez no es desesperanzadora: el fracaso de una utopía concreta no anula toda utopía. Solo la comprensión de lo existente como un límite insalvable y solo la satisfacción dentro de ese presente podrían llevar al fin de la utopía como fin de los proyectos de transformación de lo real. Si hay insatisfacción e incluso disgusto con el presente, la utopía no ha muerto: no se puede vivir sin «metas, sueños, ilusiones o ideales, sin tratar de trascender lo realmente existente. No se puede vivir, por tanto, sin utopías» 
(Sánchez Vázquez 1999: 280). En este sentido, resultan esperanzadoras las palabras de Gaos cuando dice que «los que se complacen en ver en la cordura final y muerte de don Quijote el "antiquijotismo" de Cervantes solo ven una verdad parcial. Olvidan que la postrer cordura del hidalgo es simultánea a la renaciente locura de su escudero, definitivamente quijotizado» (Gaos 1987b: 187):

No se muera vuestra merced, señor mío, sino tome mi consejo, y viva muchos años; porque la mayor locura que puede hacer un hombre en esta vida es dejarse morir sin más ni más, sin que nadie le mate, ni otras manos le acaben que las de la melancolía. Mire no sea perezoso, sino levántese desa cama, y vámonos al campo vestidos de pastores, como tenemos concertado: quizá tras de alguna mata hallaremos a la señora doña Dulcinea desencantada, que no haya más que ver. Si es que se muere de pesar de verse vencido, écheme a mí la culpa, diciendo que por no haber yo cinchado mal a Rocinante le derribaron; cuánto más que vuestra merced habrá visto en sus libros de caballerías ser cosa ordinaria derribarse unos caballeros a otros, y el que es vencido hoy ser vencedor mañana. (Cervantes 1987 [II, 74]: 1037)

En definitiva, de acuerdo con lo anterior, Sánchez Vázquez reclama tanto un discurso utópico directo como indirecto en el Quijote. El directo estaría en el fragmento citado en que don Quijote se dirige a los cabreros, y el indirecto estaría diseminado a lo largo del resto de la obra, en las aventuras del ingenioso hidalgo vistas como «el intento fracasado de realizar el contenido utópico de ese discurso» (Sánchez Vázquez 1999: 261). Tal y como ha defendido Chul Park, «en El Quijote la visión utópica de Cervantes aflora en la Edad de Oro, en la Ínsula Barataria y en las repúblicas bien ordenadas» (Park 2004: 187). Por su parte, en la interesante lectura que nos ofrece Muguerza sobre la conjunción de melancolía y utopía en don Quijote, el filósofo defiende que «en última instancia, la melancolía podría llegar a ser no menos subversiva - y hasta no menos revolucionaria- que la utopía. Y en el caso de don Quijote al menos, cabría incluso ver en la melancolía la otra cara de una misma moneda junto con la utopía» (Muguerza 2010: 79).

\section{UTOPÍAS NECESARIAS}

Si la pregunta por la utopía que Sánchez Vázquez formuló tiene sentido en nuestro presente es cosa que habrá de juzgar cada cual. En mi opinión, el proceso por el que a partir de los años sesenta han proliferado las tendencias que van, con un «empeño funerario, extendiendo certificados de defunción», no ha concluido. Primero el muerto fueron las ideologías, luego, en concreto, el marxismo, después, la historia, la modernidad, el socialismo, y por último, como fin de los fines: 
el fin de la utopía. Pero ¿qué hay de verdad o de ideología en ese "fin" tan sentenciado? (Sánchez Vázquez 1999: 291). Si la utopía supone principalmente una crítica de lo existente y una alternativa social futura con un fuerte compromiso de acción, no puede tener fin mientras haya una realidad que genere incomodidad, crítica y aspiración a una vida mejor. Aunque no haya espacio aquí para desarrollarlo suficientemente, Sánchez Vázquez mantuvo su defensa de la utopía también para el presente. En distintos trabajos recalcó la necesidad de la función crítica de las utopías, además de su papel creativo y alentador para la práctica. No le parece creíble ni aceptable defender que vivimos en el mejor de los mundos posibles. Afirma rotundamente que es necesaria una alternativa que haga frente a la larga serie de problemas irresolubles en el capitalismo, como la enajenación del trabajo, el paro estructural, la expansión del capital transnacional (con las consecuencias que acarrea), además de las enormes desigualdades sociales y la perspectiva de un colapso ecológico.

No podemos dejar de preguntarnos, por tanto, por qué convivimos todavía hoy con esa decadencia de la utopía como alternativa al capitalismo que señala Sánchez Vázquez. Sin duda los motivos son complejos, pero entre ellos podemos destacar el escepticismo y el desencanto de parte de la izquierda con la experiencia del socialismo soviético del siglo xx; y también la exitosa maniobra de naturalización del capitalismo que desde principios de los años noventa se ha acompañado de la ridiculización de cualquier alternativa. A esto precisamente se refiere Francisco Fernández Buey cuando considera que «ser utópico está bien visto a condición de que uno confiese al mismo tiempo que su sociedad alternativa (más justa, más igualitaria, más habitable) no es de este mundo» (2014: 74-75). Es decir, que las utopías, en nuestros días, pueden estar bien como ejercicio mental o pasatiempo teórico, siempre que su realización ni siquiera se plantee. El filósofo Frank Hinkelammert lo expresa de forma brillante en su Crítica de la Razón Utópica:

Una vez creado su mundo transformado, el neoliberalismo ha creado "un mundo cuya conservación vale la pena". Declara, entonces, el "fin de la historia" y la ilegitimidad absoluta de cualquier crítica de las condiciones presentes de vida. Por eso, en nombre de la utopía conservadora, esta sociedad declara ser una sociedad para la cual no hay alternativas. La crítica busca alternativas; la negación de la crítica, en cambio, se deriva de la tesis de que la sociedad afirmada es la única alternativa, para la cual no existe ninguna otra. La crítica es transformada en algo absurdo, en un asunto de tontos o de traicioneros. De allí que las sociedades que se legitiman mediante utopías conservadoras sean expresamente anti-utópicas. La utopía conservadora siempre se hace presente en nombre del realismo. [...] Los utopistas del actual Mundo Libre, tan dogmatizado por la utopía neoliberal, son todos aquellos que insisten en la posibilidad de alternativas para el camino al abismo por el que la política del mercado total nos está llevando. (Hinkelammert 2002: 296-297) 
Exactamente cuatrocientos años después de la publicación de la segunda parte del Quijote, necesitamos más quijotes que nunca. En palabras de Nabokov:

Don Quijote es más importante hoy de lo que era en el vientre de Cervantes [...]. Ya no nos reímos de él. Su escudo es la piedad, su estandarte es la belleza. Representa todo lo que es amable, las causas perdidas, lo puro, altruista y noble. La parodia se ha convertido en modelo ${ }^{3}$.

Recibido: $12 / 06 / 2015$

Aceptado: 27/10/2015

\section{OBRAS CITADAS}

Cervantes SaAvedra, Miguel de (1987). El Ingenioso Hidalgo Don Quijote de La Mancha. Edición crítica y comentarios de Vicente Gaos. Madrid: Gredos.

FERnÁNDEZ BueY, Francisco (2014). Filosofar desde abajo. Edición de Jordi Mir y Víctor Ríos. Madrid: Los Libros de la Catarata.

Gaos, Vicente (1987a). «Cervantes y la Iglesia». En El Ingenioso Hidalgo Don Quijote de La Mancha. Edición crítica y comentarios de Vicente Gaos. Volumen III. Madrid: Gredos, pp. 122-161.

(1987b). «La locura de Don Quijote». En El Ingenioso Hidalgo Don Quijote de La Mancha. Edición crítica y comentarios de Vicente Gaos. Volumen III. Madrid: Gredos, pp. 162-188.

Hinkelammert, Franz (2002). Crítica de la razón utópica. Bilbao: Desclée de Brouwer.

Maravall, José Antonio (1976). Utopía y contrautopía en El Quijote. Santiago de Compostela: Pico Sacro.

Muguerza, Javier (2010). «Utopía y melancolía en don Quijote». Logos. Anales del Seminario de Metafísica, vol. 43, pp-63-82.

Nabokov, Vladimir (1983). Lectures on Don Quixote. Edited by Fredson Bowers. Nueva York: Harcourt Brace Jovanovich.

PARK, Chul (2004). «La república utópica en El Quijote». Revista de Educación, número extraordinario "El Quijote y la educación” (coordinación de Gabriel Janer Manila), pp. 177-187.

SÁNCHEZ VÁzQuEZ, Adolfo (1975). Del socialismo científico al socialismo utópico. México: Era.

(1999). Entre la realidad y la utopía. Ensayos sobre política, moral y socialismo. $1^{\mathrm{a}}$ edición. México: Fondo de Cultura Económica.

(2007). Don Quijote como utopía. Málaga: Fundación General de la Universidad de Málaga.

3 «Don Quixote is greater today than he was in Cervante`s womb. [...] We do not laugh at him any longer. His blazon is pity, his banner is beauty. He stands for everything that is gentle, forlorn, pure, unselfish, and gallant. The parody has become paragon» (Nabokov 1983: 112). 


\section{\%}

El Quijote como utopía necesaria: la mirada de Adolfo Sánchez Vázquez

Resumen: este artículo estudia la concepción del Quijote como utopía, tal y como lo consideró el pensador Adolfo Sánchez Vázquez. Para ello será necesario analizar el poliédrico concepto de utopía para acercarnos a la definición que del mismo tiene Sánchez Vázquez. A partir de ahí, tratará de ver en qué sentido podría leerse como utopía la obra magna de Cervantes y cuáles serían sus principales características utópicas. Finalmente, concluiría con un apartado dedicado a la vigencia de este tipo de utopías en nuestros días. Palabras clave: Utopía, Adolfo Sánchez Vázquez, Quijote, crítica social, alternativas.

Quixote as a necessary utopia: Adolfo Sánchez Vázquez's view

AbSTRACT: This paper explores Adolfo Sánchez Vázquez's reading of Don Quixote as a utopia. To that purpose, it is necessary to examine the notion of utopia and its interpretation by the Spanish exiled thinker. On that basis, this work inquires into the main utopian elements in Cervantes' magnum opus and its whole construction as a utopia. The final section discusses the current relevance and validity of such type of utopias.

Key words: Utopia, Adolfo Sánchez Vázquez, Don Quixote, social critique, alternatives. 
TERESA DE JESÚS (1515-1582)

Guillermo Serés (Universidad Autónoma de Barcelona)

La imaginación de Santa Teresa: virtudes y desatinos de «la loca de la casa»....... 11

Ana Garriga EsPino (Universidad Autónoma de Madrid)

El desafío editorial de las cartas de Teresa de Jesús.

LeCTURAS REPUBLICANAS DEL QUIJOTE

RAQUEL ArIas (Universidad Autónoma de Madrid)

León Felipe alista a don Quijote en el bando republicano. 57

MANUEl LóPez ForJas (Universidad Autónoma de Madrid)

El Quijote y la realidad viva de las Españas: la visión histórica

de Pedro Bosch-Gimpera.

CArmen Madorrán Ayerra (Universidad Autónoma de Madrid)

El Quijote como utopía necesaria: la mirada de Adolfo Sánchez Vázquez 85

\section{OTROS TEMAS}

SònIA BoADAS (Universitat Autònoma de Barcelona)

Libros y librerías: la recepción de Commynes en España 101

Lucila Lobato Osorio (Universidad Nacional Autónoma de México)

La noticia de la muerte de Policisne de Boecia: expresiones de dolor en un libro inconcluso.

María Gutiérrez Padilla (Universidad Nacional Autónoma de México)

La escenografía en el teatro caballeresco 131

ADRIÁn FERnÁNDEZ (Université de Fribourg)

Dos entremeses «auditivos» y sus niveles: hacia un metateatro visual. 145

David González de la Higuera Garrido (Universidad Complutense de Madrid) La visión premonitoria de Alonso en El caballero de Olmedo:

otra recuperación de lo popular

Esther Fernández LóPEz (UNED)

Perseo en la comedia tardobarroca: Ignacio Ferrera y Pasqual 169

Manuel Piqueras Flores (Universidad Autónoma de Madrid)

De La hija de Celestina $a$ La ingeniosa Elena: estructura narrativa, género literario e interpolación 
Dagoberto CÁceres Agullar (Western University Canada)

Realismo incesante: desde Celestina hacia su recepción 201

TeXTOS INÉDITOS

Davinia Rodríguez Ortega (Universidad Pública de Navarra)

Auto sacramental del Juego del Hombre, de Luis Mejía de la Cerda:

edición crítica 


\section{EDAD DE ORO}

Revista de Filología Hispánica XXXIV

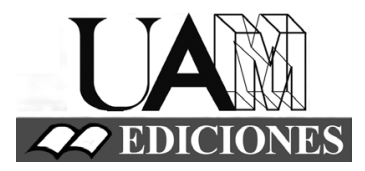




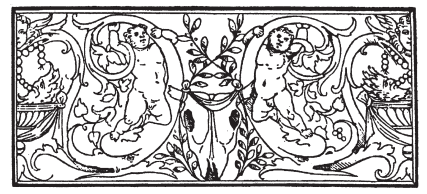

\section{Edad de Oro. Revista de Filología Hispánica}

ISSN: 0212-0429

Dirección:

Teodosio Fernández

Secretaría y edición:

José Ramón Trujillo

Comité científico internacional:

Carlos Alvar (Univ. de Ginebra)

Ignacio Arellano (Univ. de Navarra)

Javier Blasco (Univ. de Valladolid)

Alberto Blecua (UAB)

Jean Canavaggio (Univ. de París X)

Laura Dolfi (Univ. de Turín)

Aurora Egido (Univ. de Zaragoza)

Víctor García de la Concha (RAE)

Luciano García Lorenzo (CSIC)

Joaquín González Cuenca (Univ. de Castilla-

La Mancha)

Agustín de La Granja (Univ. de Granada)

Begoña López Bueno (Univ. de Sevilla)

Michel Moner (Univ. de Toulouse III)

Joan Oleza (Univ. de Valencia)

Alfonso Rey (Univ. de Santiago)

Lina Rodríguez Cacho (Univ. de Salamanca)

Leonardo Romero Tobar (Univ. de Zaragoza)

Aldo Ruffinatto (Univ. de Turín)

Lía Schwartz (City University of New York)
Redacción y admisión de originales:

Teodosio Fernández

Edad de Oro

Departamento de Filología Española

Universidad Autónoma de Madrid

28049 Madrid (España)

Tfno.: +0034914974090

correo: teodosio.fernandez@uam.es

Distribución, suscripción y venta:

Servicio de Publicaciones de la UAM

Universidad Autónoma de Madrid

28049 Madrid (España)

Intercambio de publicaciones:

Biblioteca de la Facultad de Filosofía y

Letras (UAM)

Universidad Autónoma de Madrid

28049 Madrid (España)

Han colaborado en este volumen:

Departamento de Filología Española (UAM)

Facultad de Filosofia y Letras (UAM)

Edad de Oro se recoge, entre otras, en las siguientes bases de datos: SCOPUS, MLA Database, HLAS, Latindex, PIO-Periodical Content Index, ISOC, Dialnet, MIAR, ERIH, DICE, Sumaris CBUC, Ulrich's. Se encuentra evaluada en CIRC: A; INRECH; MIAR difusión ICDS live: 9.977; SCImago Journal \& Country Rank: H Index 2, SJR 0,101, Q4; RESH índice de impacto: 0.041; ERIH: A INT1; Carhus Plus+ 2014: C. 